\title{
新エネルギーサイクルに向けた高効率太陽励起レーザーの開発
}

舩津 貴行 ${ }^{1}$ ，矢部 孝 ${ }^{1,2}$, 吉田 國雄 ${ }^{2}$, 内田 成明 ${ }^{2}$, 大久保 友雅 ${ }^{1}$, BAGHERI Behgol ${ }^{1}$, 大石 剛弘 ${ }^{1}$, 大東 和也 ${ }^{1}$, 石岡 学 ${ }^{1}$, 安永 $\bar{c}^{2}{ }^{1}$, 佐藤 雄二 ${ }^{2}$, BAASANDASH Choijil ${ }^{2}$,

加藤 洌 ${ }^{3}$, 柳谷 高公 ${ }^{4}$, 岡本 義昭 $^{5}$

${ }^{1}$ 東京工業大学 ( $\bar{\top} 152-8552$ 東京都目黒区大岡山2-12-1)

${ }^{2}$ Entropia レーザー Initiative（テ152-8552 東京都目黒区大岡山2-12-1）

3 千歳科学技術大学 ( $\bar{T} 066-8655$ 北海道千歳市美々 758-65)

4 神島化学工業(株)（７69-1103 香川県三豊市宅間町香田80番地）

${ }^{5}$ (有) 岡本光学加工所 ( $=235-0008$ 神奈川県横浜市磯子区原町8-34)

\section{Development of Solar Pumped Laser for New Energy Cycle}

Takayuki FUNATSU, ${ }^{1}$ Takashi YABE,${ }^{1,2}$ Kunio YOSHIDA, ${ }^{2}$ Shigeaki UCHIDA, ${ }^{2}$ Tomomasa OHKUBO, ${ }^{1}$ Behgol BAGHERI, ${ }^{1}$ Takehiro OISHI, ${ }^{1}$ Kazuya DAITO,${ }^{1}$ Manabu ISHIOKA, ${ }^{1}$ Norihito YASUNAGA, ${ }^{1}$ Yuji SATO,${ }^{2}$

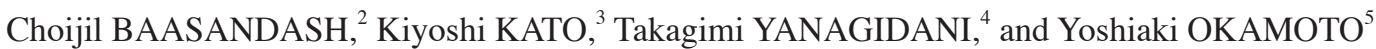

${ }^{I}$ Department of Mechanical Sciences and Engineering, Tokyo Institute of Technology, 2-12-1 O-okayama, Meguro-ku Tokyo, 152-8550 ${ }^{2}$ Entropia Laser Initiative, Tokyo Institute of Technology, 2-12-1 O-okayama, Meguro-ku, Tokyo 152-8552

${ }^{3}$ Chitose Institute of Technology, Bibi 758-65, Chitose, Hokkaido, 066-8655

${ }^{4}$ Konoshima Kagaku Co. Ltd., 80 Koda, takumachou, Miyoshi, Kagawa, 769-1103

${ }^{5}$ Okamoto Optic Co, 8-34 Haramachi, Isogo-ku, Yokohama, Kanagawa, 235-0008

(Received September 26, 2008)

\begin{abstract}
A new type of solar-pumped laser system characterized by high efficiency and low cost was developed using a newly designed Fresnel lens and a Cr codoped Nd:YAG ceramic laser medium. A 4-m ${ }^{2}$ Fresnel lens was designed to collect wavelengths in the visible range of sunlight (400 to $900 \mathrm{~nm}$ ). A solar chamber was designed to efficiently couple the collected sunlight to a rod-shaped laser medium. Laser output of about $80 \mathrm{~W}$ has been achieved with a combination of the Fresnel lens and solar chamber. The maximum output from a unit area of the Fresnel lens was $20 \mathrm{~W} / \mathrm{m}^{2}$, which is 2.8 times larger than the previous results with a mirror type concentrator.
\end{abstract}

Key Words: Solar pumped laser, Fresnel lens, Nd YAG, Cr Nd:YAG ceramic, Energy cycle

1.はじめに

化石燃料に代わる新しいエネルギー源の開発は差し 迫った問題である。枯渇の心配がなく地球環境への影響 が最小となる再生可能エネルギーの活用が望まれる。再 生可能エネルギーの中で最大のものは太陽からの直接光 エネルギーである。例えば，数万 $\mathrm{km}^{2} に$ 注ぐ太陽光パ ワーは全世界の電力消費に匹敵する。しかしながら，太 陽エネルギーはパワー密度が低く，不安定性が問題であ り完全な太陽光エネルギー社会を実現する上で課題と なっている，さらに，太陽光が利用できるのは晴天の日 中だけであるため，基幹エネルギー源として成立するた めには大規模電力貯蔵システムが必要不可欠である.

そこで，著者らは太陽エネルギーを金属マグネシウム の形で貯蔵し，必要に応じて燃料として利用するサイク ルを提案している ${ }^{1)}$.この新エネルギーサイクルでは,
水とマグネシウムの反応などから水素と熱エネルギーが 生成され，燃料電池や熱機関などに応用できる。マグネ シウムの賦存量は地殼中では8番目, 海水中の金属とし ては2番目 $\left(1.8 \times 10^{15}\right.$ tons $)$ と膨大である。またエネル ギー密度も化石燃料と同程度であり燃料として有利であ る。 反応後のマグネシウムは酸化マグネシウム $(\mathrm{MgO})$ として固体のまま手元に残るので，炭酸ガスのように大 気に拡散して地球環境に影響を及ぼす心配がない. $\mathrm{MgO}$ を還元 (製錬)してマグネシウムに再生することに よりエネルギーサイクルが完結する。しかしながら， $\mathrm{MgO}$ を効率よく還元するには $4000 \mathrm{~K}$ 高温が必要であ り，その実現には $10^{5} \mathrm{~W} / \mathrm{cm}^{2}$ 程度のパワー密度が必要で ある2)。この条件を満たし，かつ，自然エネルギーを用 いるには，太陽励起レーザーが最適である。この化石燃 料を使用しないエネルギーサイクル実現のためには， 0.5-1 kWの太陽励起レーザーユニットの開発で十分であ 
る.太陽光を基幹エネルギーとして利用するためには, このユニットを必要数並べてマグネシウム還元工場を建 設すればよい.

太陽励起レーザー研究の歴史は古く，1965年に米国の C. G Young によって初めて報告された ${ }^{3)}$ 。彼らは, 太陽 光をパラボラ反射鏡で集光してロッド型レーザー媒質よ り $1.3 \mathrm{~W}$ の連続波 ( $\mathrm{cw}$ )レーザー発振に成功している。そ の後, 現在まで様々な方式による太陽励起レーザーの発 振が報告されている ${ }^{4-6)}$. V. Krupkin et al. はNd:YAG (yttrium aluminum garnet) レーザー媒質と $660 \mathrm{~m}^{2}$ の集光鏡を用 いてレーザー出力, $500 \mathrm{~W}$ 達成している7). しかしな がら，鏡へ入射した太陽光から $1064 \mathrm{~nm}$ の変換効率は $0.1 \%$ 以下と低い. このように, 従来の太陽励起レー ザーは全て, 集光装置に放物面鏡やへリオスタットなど の反射光学系が用いられている。 これらの装置は大量の 熱を集積する太陽熱利用の施設や望遠鏡を援用したもの で，必ずしもレーザー励起に適したものではない．太陽 励起レーザーシステムを大規模なエネルギーサイクルの 中で考えると, 「適当な大きさのユニットレーザー装置 をアレイ状に配置したプラント」という考え方が有効で ある。

一方，太陽光は可視域波長をピークに持つ幅広いスペ クトルをもつので, レーザー媒質にはこの可視域波長の 光を有効に利用することが求められる. 太陽および類似 のランプ光源のスペクトルを幅広く吸収して, レーザー への変換効率を改善するためNd:YAGにCr ${ }^{3+}$ イオンを ドーパントとして加える指摘は以前よりあったが, 従来 の結晶成長の技術では困難であった ${ }^{8)}$. Ikesueらはセラ ミック技術を用いてCrドープNd:YAGレーザー媒質の開 発に成功した9)。実際の太陽光を用いた実験では, 実験 室内では考えられない困難に遭遇する。屋外では, 風に よって常に装置全体が摇れ動いたり, 大気中の散乱や屈 折によって, 太陽光パワーが時々刻々と変化する。著者 らはこうした悪条件の中で, 世界で初めてCr:Nd:YAG七 ラミックレーザー媒質(以下， Cr:Nd:YAG)を用いたレー ザー発振に成功した ${ }^{2,10)}$.

著者らは安価で軽量なフレネルレンズを用いて, 高効 率で経済的な特長を持つ新しい太陽励起レーザーシステ ムを開発している。これまでに, $1.3 \mathrm{~m}^{2}$ のフレネルレン ズを用いてレーザー出力 $24.4 \mathrm{~W}$ を得ている．このときの 装置の太陽光受光面積に対する最大出力は $18.7 \mathrm{~W} / \mathrm{m}^{2}$ で ある ${ }^{10)}$.

本論文では，レーザー媒質やフレネルレンズについて 本実験で実現した太陽励起レーザーの特徴を記述する。

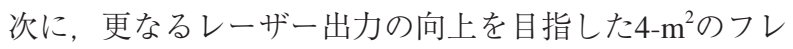
ネルレンズを用いたレーザー発振の結果を示す。この実 験結果から, 現状のレーザーのパワーに寄与している吸 収の特性について検討を行なったので報告する。

\section{2. フレネルレンズを用いた太陽励起レーザーの開発}

\section{$2.1 \mathrm{Cr}: \mathrm{Nd}: Y A G$ 媒質の吸収スペクトル}

Cr:Nd:YAGは太陽光スペクトルに適した吸収スペクト
ルを有し，発振波長も近赤外領域にあるため高い光変換 効率が期待できる。 また，固体レーザーの特徵である高 い活性イオン種密度によりコンパクトなレーザー装置が 実現可能で，大量のエネルギー変換を行うプラントの要 素デバイスとして適している。Fig. 1に太陽光スペクト ルと Nd:YAG結晶, $\mathrm{Cr}: \mathrm{Nd}: \mathrm{YAG} の$ 吸収係数を示す。太陽 光スペクトルは, 地上に到達する直達パワー強度を, 波 長 $1 \mathrm{~nm}$ ごとに示している ${ }^{11)}$.太陽は可視域波長をピーク に持つ幅広いスペクトルである。 $\mathrm{Nd}: \mathrm{YAG}($ ドープ濃度 $\mathrm{Nd}$ : 約 $1 \%$ ) 結晶と Cr:Nd:YAG (ドープ濃度Cr: $0.1 \%, \mathrm{Nd}$ : $1 \%)$ セラミックの吸収係数は分光光度計 (JASCO-V-530) を用いて測定した結果である。400-500 nm, 600-650 nm の波長域でCr:Nd:YAGの方がNd:YAG媒質に比べて大き な吸収が見られる。Cr添加による可視域の吸収が $1064 \mathrm{~nm}$ の蛍光に寄与していることが報告されており, 太陽光全体のスペクトルからの寄与を積算すると $\mathrm{Cr}$ ドー プにより $\mathrm{Nd}$ みの場合の約 2 倍の蛍光強度を持つことが わかっている ${ }^{10)}$. これらの結果より，太陽光の可視域波 長を有効にレーザーへ変換できる媒質として, $\mathrm{Cr}: \mathrm{Nd}$ : YAGは優れた材料であることがわかる.

\section{2 フレネルレンズの特徴}

従来の太陽励起レーザーの集光装置は，放物面鏡やへ リオスタットなどの反射型光学系を使用している。しか し, 反射型光学系は重量が重く, 光学面の研磨や蒸着が 必要であり製作コストが高い。一方，フレネルレンズの 断面はFig. 2に示すように微小プリズムを並べた構造を 持ち, 球面レンズの斜線部を除去した形状になっている ことと, 型押し成型で大量生産が可能であるため, 安価 で軽量である。一般的には, 灯台, 画像プロジェクター やリアプロジェクションテレビに利用されている。単純 な屈折型集光素子は色収差を持つため太陽光の集光には 不利とされてきたが，太陽光の集光系では色収差は

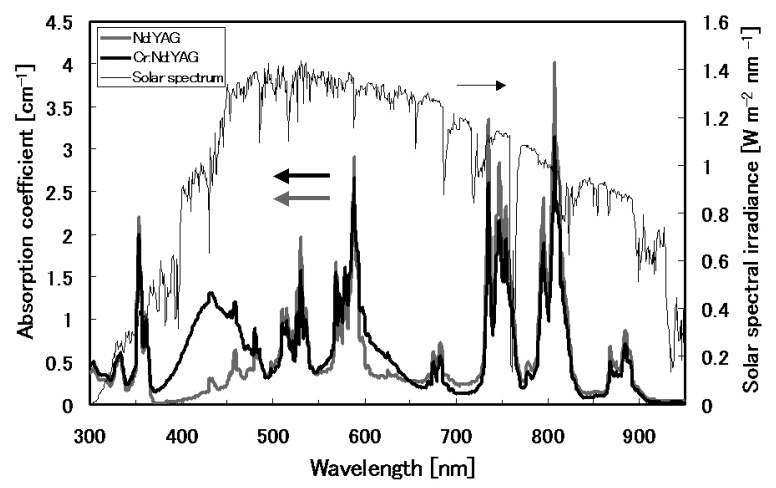

Fig. 1 Absorption coefficient of Nd:YAG \& Cr:Nd:YAG, and the solar spectrum. ${ }^{11)}$

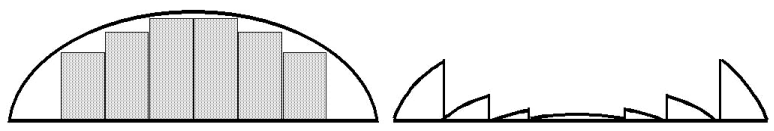

(a)

(b)

Fig. 2 Cross section of a conventional plano-convex lens: (a) and the Fresnel lens: (b). 
$10 \%$ 程度の影響に留まり無視できる。

Fig. 3に石英ガラス $\left(\mathrm{SiO}_{2}\right), \mathrm{BK} 7$, Poly methyl methacrylate (PMMA)の透過率を示す。このPMMAは, 我々がフ レネルレンズに採用したアクリル樹脂板 (三菱レーヨン (株)：アクリライト\#001)である.PMMAの透過率は レーザー発振に有効な $350 \mathrm{~nm}$ から $900 \mathrm{~nm}$ の波長域で $\mathrm{SiO}_{2}$ と同等の $90 \%$ 以の透過率を有していることがわか る。さらに, BK7は $250 \mathrm{~nm}$ 以下の紫外域波長を吸収する のに対し，PMMAでは350 nm以下を吸収するため， レーザー媒質のソラリゼーション防止に有効である。ま た, PMMAはプラスチック材料であるため, 大量生産 が可能である。フレネルレンズにPMMAを採用した場 合, PMMA自身の紫外線による劣化が懸念されるが, 我々が使用したPMMAは紫外線吸収剂によって耐光性 を向上させたアクリル樹脂板であり，実際に晴天の日に 1 年以上屋外で使用していても集光パワーへの影響は無 かった.これらの結果より, フレネルレンズの材料に PMMAは有効である.

\section{3. フレネルレンズによる集光特性}

高効率な太陽励起レーザーの開発には，集光系に入射 する太陽光パワーとレーザー媒質へ集光される光強度を 高める必要がある。集光系に入力される太陽光パワーを 高めるには，レンズの面積を大きくすればよいが，集光 された光強度を上げるには $F$ 值 $=f / D(f$ : 焦点距離, $D$ : レンズ直径)を小さくする必要がある。しかしながら $\mathrm{F}$ 值の小さなレンズは光の入射角が大きくなり反射損失が 増大する，そこで，本論文ではF值 $=1$ の 2 つフレネル レンズを用いて，太陽励起レーザーの発振を実証した。 1つは, 市販されているリアプロジェクション用の投影 レンズ, Fresnel lens (a): FL(a)である。大きさは $1.4 \times 1.05 \mathrm{~m}$, 焦点距離 $f=1.2 \mathrm{~m}$ で日本特殊光学樹脂 (株) 製である。もう一方は，著者らが設計してレンズを大型 化したFresnel lens（b): FL（b)である．大きさは $2.0 \times 2.0$, $f=2.0 \mathrm{~m}$ のレンズである.ここでは両者を比較しなが ら，設計のコンセプトと実際に太陽光を集光させたとき のレンズの特性について述べる。

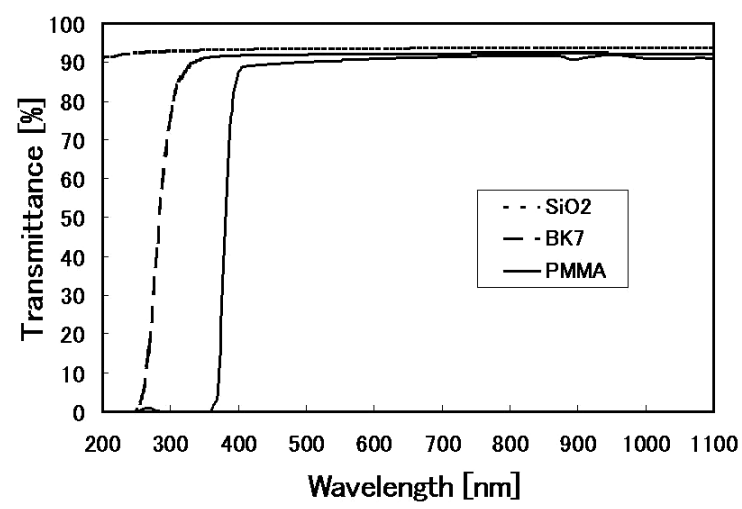

Fig. 3 Transmittance of the $\mathrm{SiO}_{2}$, BK7 and PMMA (The thickness of samples is $2.0 \mathrm{~mm}$ ).

\section{1 平面入射フレネルレンズの特徴}

一般に使われているフレネルレンズはリアプロジェク ションTVに用いられるように，点光源を平行化するよ うに設計されている.よって, Fig. 4 (a)に示すように, 集光用にフレネルレンズを用いる場合，凸面から太陽光 を入射させるため, 図に示した斜線部では損失 (shadow loss）が生じる。また，このようなレンズの平面側から 太陽光を入射させると，F值が約 1.15 以下であると全反 射が生じる，FL (a)はこのタイプであるので，太陽光を 凸面から入射させるとshadow lossが生じ，平面側から入 射させるとレンズの外周部は全反射によって集光できな い部分が存在する。近年ではフレネルレンズを用いた太 陽光集光の研究は盛んになっており, Fig. 4(b)に示すよ うな, レンズの平面側から太陽光を入射させるフレネル レンズが採用されている ${ }^{12-13)}$ ，そこで，レンズの平面か ら太陽光を入射して集光するレンズの透過率を検討し た，F值をそれぞれ変化させ，凸面入射と平面入射のレ ンズ透過率を計算により比較した(Fig. 5). 平行光をレ ンズに入射させた場合を想定し，幾何光学とフレネル反 射の公式を用いて反射損失と前述のshadow lossのF值依 存性を計算した。太陽パワーのピーク波長を考慮し, 460-600 nmに対応するPMMAの屈折率1.49を使用した。

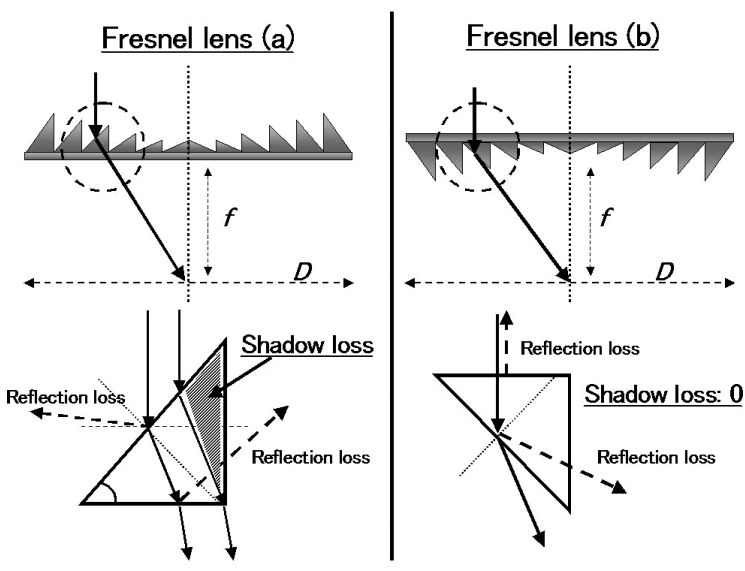

Fig. 4 Concept of 2 types of Fresnel lens, (a) Conventional Fresnel lens, (b) Fresnel lens for solar light concentration.

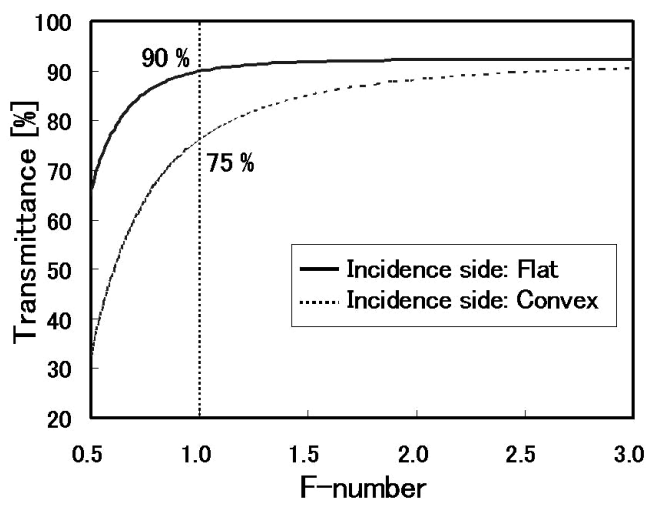

Fig. 5 Comparison of calculated transmittance the conventional Fresnel lens with the Fresnel lens of solar light concentration by changing F-number. 
反射損失はP偏光と $\mathrm{S}$ 偏光の平均值とした。この結果, 透過率は凸面入射に比べて平面入射が常に反射損失が低 く, $F$ 值 $=1$ のとき平面入射型では透過率が漸近值 $90 \%$ にほぼ達しており, 本研究のフレネルレンズも F值 $=1$ で作製した。

\section{2 集光径の測定}

前述のように太陽励起レーザーの集光レンズには F 值 を小さくする必要があるため色収差の影響を光線追跡法 により評価した。まず，評価の基準となる理想的なレン ズから得られる無収差の太陽像は次のように求められ る.太陽は有限の大きさを持っており, 集光像も有限の 大きさを持つ。この理想的な集光像の直径は式(1)で表 すことができる。

$$
D_{\text {focus }}=D_{\text {sun }} \times \frac{f}{L}
$$

ここで $D_{\text {sun }}=1.39 \times 10^{9} \mathrm{~m}$ は太陽の直径, $L=1.50 \times 1011 \mathrm{~m}$ は太陽と地球の距離を表す。レンズの焦点距離 $f=2.0 \mathrm{~m}$ とすると $D_{\text {focus }}=18.5 \mathrm{~mm}$ である。方，太陽の大きさ と地球との位置関係からフレネルレンズ側から見ると太 陽光は $4 \mathrm{mrad} の$ 広がり角を持つ。この光線の広がりを考 慮した光線追跡によるレンズの焦点でのパワー分布を Fig. 6に示す。レーザー媒質に吸収される400-850 nmの 波長範囲を $10 \mathrm{~nm}$ 毎に分割し, 各波長に対して25000本 の光線ベクトル方向を太陽光の広がり角内でランダムに 分布させフレネルレンズに入射させ光線追跡を行った。 計算の結果, $\mathrm{FL}(\mathrm{b})$ の集光点でのパワー分布の半值全幅 (FWHM) は20 mmとなり， $D_{\text {focus }}$ との比較により色収差 $1.5 \mathrm{~mm}$ 程度と判明した。

Fig. 7にフレネルレンズの集光点で測定した太陽光ス ポットの強度分布を示す。測定には水冷式の $\phi 3 \mathrm{~mm} の \mathrm{Al}$ 製アパチャーを付けたサーモパイル型のパワーメータを 使用した。パワーメータを集光面に沿って $2 \mathrm{~mm}$ 毎に20 秒ずつ走査させて測定した。 アパーチャーが水冷式であ るのは，集光されたパワーによりアパーチャーが加熱さ れ，その輻射によりパワーメータが影響を受けることを 防ぐためである.フレネルレンズの集光径はFWHMで 約 $21 \mathrm{~mm}$ であり，計算によるフレネルレンズの焦点での 集光スポットの大きさとほぼ一致している.

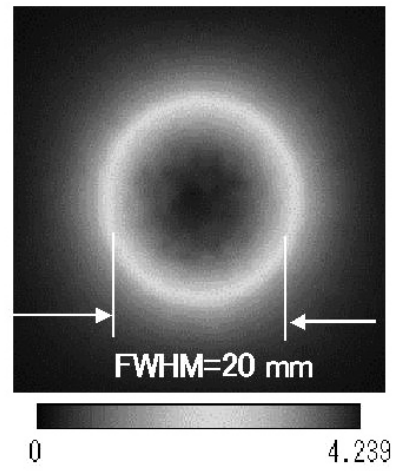

Fig. 6 Power distribution at the focal point of FL(b) by ray tracing simulation.

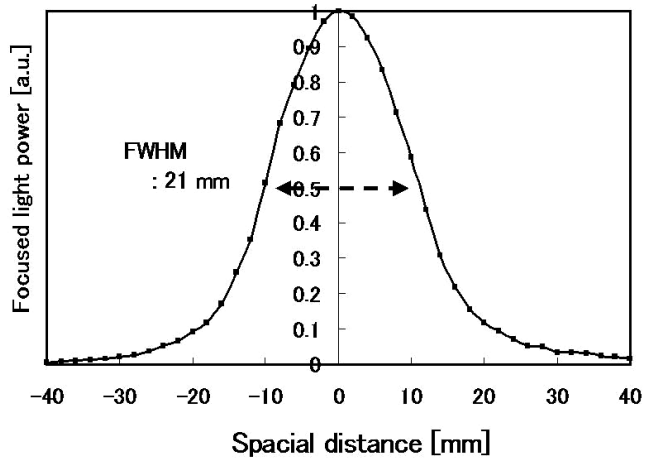

Fig. 7 Focused sunlight power distribution at the focal point of FL(b) measured by thermopile-type power meter.

\section{3 集光効率の測定}

$\mathrm{FL}$ (a) およびFL (b)の集光効率と集光パワーの測定を 行った.太陽光の入射方向はそれぞれのレンズの設計通 り，FL (a) は凸面から太陽光を入射させ, FL (b) は平面 側から入射させる. Fig. 8に測定方法を示す。フレネル レンズの焦点位置にパワーメータを設置して, 集光パ ワーを測定する。同時に, フレネルレンズ表面に入射し たパワーを直達日射計を用いて測定する。フレネルレン

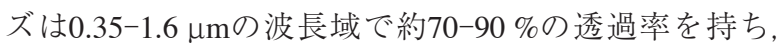
太陽光は1.6 $\mu \mathrm{m}$ 以下の波長域で全体の90\%程度のパワー 密度を占める。直達日射計は(株)プリード製 $\mathrm{CH} 2$ (受光

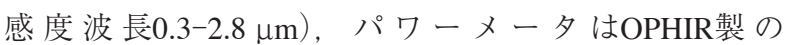
L1500W(受光感度波長0.19-20 $\mu \mathrm{m}$ ) を使用した。集光効 率と集光パワーの結果をTable 1 に示す。集光点における パワーの測定面積は, 集光した太陽像のサイズが各レン ズの焦点距離に応じて変化することを考慮しなければな らない. そこで, FL (b)の集光パワーの測定面積はFig. 7 に示した集光位置でのパワー分布を十分に測定できる $\phi 80 \mathrm{~mm}$ とた. FL (a)については集光パワー分布を考慮 し $850 \mathrm{~mm}$ とした ${ }^{10)}$ 。その結果，FL(a)の集光効率は64\% であるのに対し，FL（b)の集光効率は47\%であった。一 方, 直達太陽光パワー密度が $922 \mathrm{~W} / \mathrm{m}^{2}$ の時, FL (a)の集 光パワーは867 WであったＦL (b) を用いた時は989 $\mathrm{W} / \mathrm{m}^{2}$ の時，1860 Wを得た。これらのパワー值を実測で きた集光パワーの最大值とした．太陽光パワーは日時に よって異なるため, それぞれのレンズの効率を考慮し, $1000 \mathrm{~W} / \mathrm{m}^{2}$ の直達太陽光パワー密度を仮定した時の集光

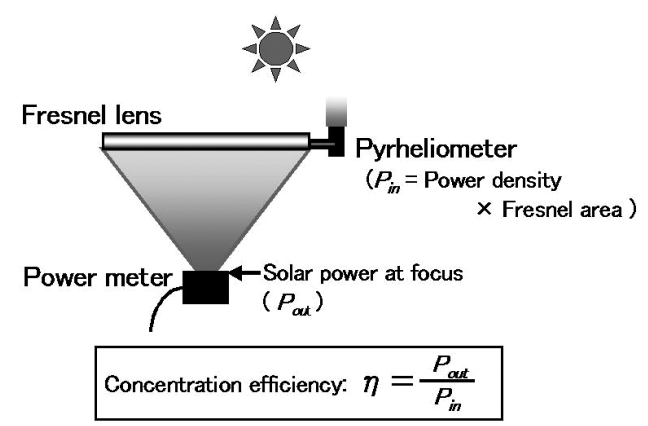

Fig. 8 Setup of measuring the concentration efficiency of Fresnel lens. 
Table 1 Concentration efficiency and maximum power at focal point of each Fresnel lens.

\begin{tabular}{cccc}
\hline Fresnel lens & Concentration efficiency & Max power at focal position & Direct solar intensity \\
\hline FL(a) & $64 \%$ & $867 \mathrm{~W}$ & $922 \mathrm{~W} / \mathrm{m}^{2}$ \\
FL(b) & $47 \%$ & $1860 \mathrm{~W}$ & $989 \mathrm{~W} / \mathrm{m}^{2}$ \\
\hline
\end{tabular}

パワーを比較すると, FL (b) が1880 W, FL (a) が940 W となり，2倍の差があるのでレーザーの出力パワーの増 加が期待できる、新たに製作したFL (b)の集光効率がFL (a)より低い原因として，レンズの成型時に生じたレン ズ表面の凹凸が考えられ，現在改良を試みている。

\section{4. 太陽励起レーザーの発振特性}

\section{1 実験装置図}

Fig. 9に太陽追尾装置の写真を示す. Setup:IにFL (a), Setup:IIにFL (b) が搭載されている. Setup:Iは赤道儀方 式, Setup:IIは経緯台方式の追尾装置である。これらは 仰角，方位角をそれぞれ制御して太陽を追尾する。レー ザー発振器はフレネルレンズの集光位置に設置されてい る. Setup:Iは片方のレンズでレーザー発振, もう1つで レーザー増幅をするこが可能である。本論文では片方だ けを使用してレーザーを発振させている．太陽の追尾方 法は, 方位角方向が自動, 仰角方向は手動である. Setup:IIはラフォーレエンジニアリング(株)製の太陽光採光 システム「ひまわり」にフレネルレンズを搭載できるよう に改良した。このシステムでは搭載されたフォトセン サーを用いたフィードバック自動追尾が可能である。ま た，FL(b)は2 m角のレンズであるが，自重のたわみを 軽減するため4分割して搭載されている。

Fig. 10にレーザー発振器の概念図を示す。フレネルレ ンズの焦点に設置された励起チャンバー内に直径 $9 \mathrm{~mm}$, 長さ $10 \mathrm{~cm}$ のr:Nd:YAG媒質が保持されている. チャン バー内面は円錐型の反射鏡となっており，レーザー媒質 は集光レンズからの直接光とチャンバー内で反射された 間接光により励起される。 チャンバーはレーザー媒質自 身と $\mathrm{SiO}_{2}$ 製の太陽光入射空により密閉されており, その 中を冷却水が循環する。 また，太陽光入力側のレーザー
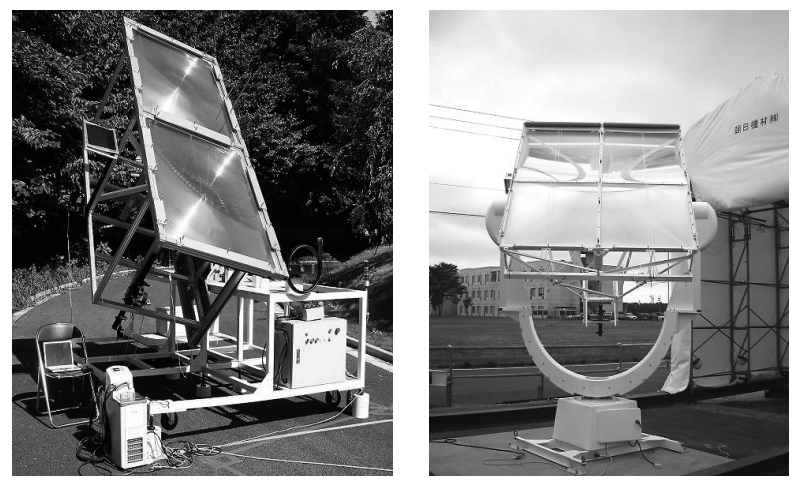

Fig. 9 Solar pumped laser on sun tracking system (Left: Setup:I, FL(a), $1.4 \times 1.05 \mathrm{~m}, f: 1.2 \mathrm{~m}$, Right: Setup:II, FL(b), $2.0 \times 2.0 \mathrm{~m}, f: 2.0 \mathrm{~m}$ ).

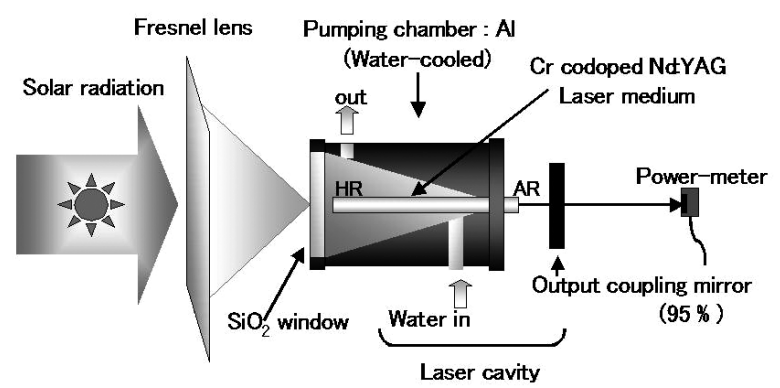

Fig. 10 Schematic view of laser head.

媒質端面には高反射コーティングが，出力側には無反射 コートが施されている. 出力ミラーは励起チャンバーの 外側に設置し, 種々の条件 (反射率, 曲率, 発振器長)で レーザー発振実験を行った。

\section{2 高効率太陽励起レーザー}

Fig. 11にキャビティーに入力する太陽光パワーとレー ザー出力の関係を示す３-3項で示したようにレンズ側 面に設置した直達日射計は集光点での太陽光パワーと較 正されており, 変動する太陽光に対して常時入射パワー とレーザーパワーを同時に計測している，スロープ効率 などの測定のため入力太陽光のパワーはフレネルレンズ 上にレンズ光軸に対称な減光マスクを被せて変化させ た。現状の励起パワー密度におけるレーザー出力ミラー の反射率はおよそ $95 \%$ が最適值である，FL (a)では，入 力太陽光パワー $867 \mathrm{~W}$ の時, 最大で $24.4 \mathrm{~W}$ を得た ${ }^{10)}$ 。著 者らが設計したFL (b) を用いた場合では，入力太陽光パ ワーが1860 Wの時，78.9Wを得た。この時の，太陽光 からレーザーへの光変換効率は約 $4.2 \%$ あるる。次節で 述べる定常状態での4準位レーザーのモデル計算で求め た動作特性を実線で示す

\section{3 レーザー出力パワーと励起状態の検討}

太陽励起レーザーの発振効率を向上させるために, 集 光レンズや励起チャンバーの改善が必要である。そこ で，これらの集光特性を加味してレーザー媒質の励起状 態を分析する。実験から得られた励起チャンバーへの入 力光パワーとレーザー出力パワーから，モード体積に寄 与する「有効長 $\rfloor L_{\text {effect }}$ を算出し, FL (a) とFL (b) の励起状

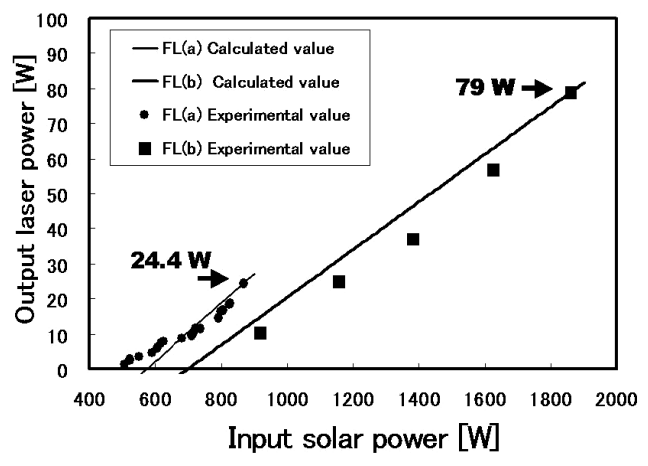

Fig. 11 Dependency of laser output on incident sunlight power and the slope efficiency. 
態について検討を行った，本研究で用いた励起チャン バー内に配置したレーザー媒質にはその軸方向に分布し た励起光が吸収されると考えられる。この場合，媒質中 に十分な励起強度が実現しない領域も含まれる可能性が ある. 解析では媒質中で発振に有効な励起強度が実現さ れている長さを有効長と定義した。この有効長を用いた 計算による実験值データ再現性の確認により解析モデル の妥当性を検証し, 理想的な励起条件におけるレーザー パワーを見積もる。

計算には定常状態の4準位レーザーの解析モデル ${ }^{14)}$ 使用した。透過率 $T_{1}$ と $T_{2}$ の鏡で組まれた共振器に対し て, $T_{2}$ 側のレーザー出力パワー $P_{\text {out }}$ は出力ミラーの損失 $-\ln \left(1-T_{2}\right)$, 共振器内の光子数 $\phi$ を用いると次式で表さ れる。

$$
P_{\mathrm{out}}=\frac{-\ln \left(1-T_{2}\right)}{2 L_{\mathrm{opt}}} C h v \phi
$$

$L_{\mathrm{opt}}$ は共振器の光学的距離 $L+(\mathrm{n}-1) L_{m}(L$ は共振器長, $n$ は媒質の屈折率, $L_{m}$ は媒質長さ)であり, Cは光速であ る. また, 共振器内の光子数

$$
\phi=V_{a} \tau_{c}\left(R_{p}-\frac{\gamma}{\sigma L_{\text {effect }} \tau}\right)
$$

ここで $V_{a}, R_{p}, \sigma$ はそれぞれ，媒質のモード体積 : $L_{\mathrm{effect}} \times A$ ( $A$ : 媒質の断面積), 励起密度, 誘導放出断面積であ る. $\tau_{c}$ は共振器内の光子寿命であり次式で表される.

$$
\tau_{c}=\frac{L_{\mathrm{opt}}}{\gamma C}
$$

ここで $\gamma$ は共振器内の片道あたりの光子の損失割合であ り, $1064 \mathrm{~nm}$ に対する媒質の損失係数を $\alpha_{1064}$ とすると次 式で表される.

$$
\gamma=\frac{-\ln \left(1-T_{1}\right)\left(1-T_{2}\right)}{2}+\alpha_{1064} L_{m}
$$

また, 式(2)と（3）より媒質断面積を励起断面積と仮定し た場合のモード体積の長さ, 有効長 $L_{\text {effect }}$ は下記のように 表せる。

$$
L_{\text {effect }}=\frac{1}{R_{p}}\left(\frac{2 L_{\text {opt }} P_{\text {out }}}{-\ln \left(1-T_{2}\right) C h v A \tau_{c}}+\frac{\gamma}{\sigma \tau}\right)
$$

この式の未知数はレーザー出力 $P_{\text {out }}$ と励起密度 $R_{p}$ であ る。 $P_{\text {out }}$ は実験值を使用する，そして， $R_{p}$ は以下に述べ るようにレーザー媒質に到達する太陽励起光強度から求 めることができる。

まず，媒質の吸収長を $d$ とした時の吸収効率 $\eta_{a b s}(\lambda)$ は 式(7)のように算出できる.

$$
\eta_{\mathrm{abs}}(\lambda)=1-\exp (-\alpha(\lambda) d)
$$

ここで $\alpha(\lambda)$ はFig. 1に示したレーザー媒質の波長依存吸 収係数である。吸収効率 $\eta_{\mathrm{abs}}(\lambda)$ と, レーザー出力時に チャンバー内に入力した太陽光パワー $P_{\text {sun }}(\lambda)$ を用いて,
吸収された光子数 $\phi_{\mathrm{abs}}(\lambda)$ を算出する。吸収された光子が レーザー上準位に遷移する確率 $\eta_{Q}(\lambda)$ を一定值 $95 \%$ と して $\phi_{\text {abs }}(\lambda)$ に掛けることにより，レーザーに寄与する光 子数の合計 $\phi_{\text {sun }}$ は式 $(8)$ となる.

$$
\phi_{\text {sun }}=\eta_{Q} \int \phi_{\mathrm{abs}}(\lambda) d \lambda=\eta_{Q} \int \frac{\eta_{\mathrm{abs}}(\lambda) P_{\mathrm{sun}}(\lambda)}{h v} d \lambda
$$

これまでの研究で, 熱電対を用いて励起チャンバー内の 媒質の軸方向に対する相対的なパワー分布を報告してい る る $^{17)}$ パワー分布は, 太陽光の入射側である前方部にフ レネルレンズによる集光で得られるピークと，レーザー 出力側に近い後方部に励起チャンバーによって再集光さ

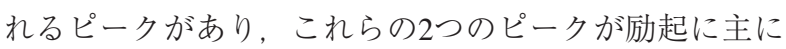
寄与していると考えられる。また，これらのピークの高 さはほぼ同一であるため, 光強度は前方のフレネルレン ズによって集光された集光パワー密度を用いる．集光パ ワー密度は, Fig. 7に示したフレネルレンズの集光位置 での光強度分布の最大值に対応することにより求めた。 この光強度分布を用いて太陽光がレーザー媒質に入射す る割合を求め, 媒質の吸収長 $(d=1 \mathrm{~cm})$ を考慮すること により媒質内の励起密度 $R_{p}$ を計算することができる. FL (a)についても，これまでに報告した集光分布 ${ }^{10)}$ から 同様に $R_{p}$ を計算した。

実験で得られたレーザー出力パワーと入射太陽光パ ワーから算出した $R_{p}$ を用いて, 式(6)より有効長 $L_{\text {effect }}$ を 算出した，励起密度の計算結果および，レーザー出力の 解析時に使用した值をTable 2 に示す。さらに，入力太陽 光パワーを変化させた場合の $R_{p}$ を算出し, それに対応す るレーザー出力を計算した結果をFig. 11に実線で示し た。

Table 2に示すように, FL (b) の励起密度が $4.3 \times 10^{20}$ 個 $/ \mathrm{cm}^{3} \mathrm{~s}$ であるのに対し, FL (a) は5.7 × $10^{20}$ 個 $/ \mathrm{cm}^{3} \mathrm{~s}$ と FL (a)でより強い励起が行われている。一方, レーザー出 力を比べると, FL (b)で78.9 Wが得られており, FL (a) の $24.4 \mathrm{~W}$ よ大きい. FL (b)で大きなレーザー出力が得 られているのは, 励起有効長がFL (a)で $1.94 \mathrm{~cm}$ に対して $\mathrm{FL}(\mathrm{b})$ では $4.6 \mathrm{~cm}$ と倍以上長いことから, 励起チャン バーの2次集光によって媒質のより多くの部分が有効に 励起されているためと考えられる. 以上の結果から，フ レネルレンズの集光パワーとレーザー出力パワーを用い て，レーザーの励起状態の評価ができた，今後は，更な る高効率化を目的として，この評価手法に基づき励起 チャンバーなどの改良を行い，媒質全体に亘って有効励 起を実現することが重要である。

$\mathrm{FL}$ (b)について, 励起チャンバーやCrドープ濃度の改 善等を行い, 入力したパワー全てをレーザー媒質に, 均 一に吸収できた場合を想定する。 入力パワーは，フレネ ルレンズの成型時に生じた凹凸を改善することによっ て, FL (b)の集光効率がFL (a) の64\%と同等になると約 $2500 \mathrm{~W}$ となり, 最大光強度は $465 \mathrm{~W} / \mathrm{cm}^{2}$ と予想できる. ここで, 励起パワーの密度が高くなった時の熱応力に耐 える媒質半径を考慮する。ロッド型のYAGの熱衝撃係 数 $R s=7.9 \mathrm{~W} / \mathrm{cm}$ と媒質長さlを用いて, 破壊に耐えられ 
Table 2 Optical parameters.

\begin{tabular}{|c|c|c|c|c|}
\hline Common parameters & & & & Reference \\
\hline Refractive index & $n$ & 1.82 & - & \\
\hline Loss coefficient & $\alpha$ & $2.00 \times 10^{-3}$ & $\mathrm{~cm}^{-1}$ & {$[15]$} \\
\hline Life time of Nd ion & $\boldsymbol{\tau}$ & 230 & $\mu \mathrm{sec}$ & [16] \\
\hline Stimulated emission cross section (Nd:YAG) & $\sigma$ & $2.80 \times 10^{-19}$ & $\mathrm{~cm}^{2}$ & {$[8]$} \\
\hline Quantum efficiency (Nd:YAG) & $\eta_{Q}$ & 95.0 & $\%$ & [8] \\
\hline Transmittance of HR & $T_{1}$ & 0.28 & $\%$ & \\
\hline Transmittance of O.C & $T_{2}$ & 5.00 & $\%$ & \\
\hline Length of medium & $L_{m}$ & 10.0 & $\mathbf{c m}$ & \\
\hline Resonator length & $L$ & 10.5 & $\mathbf{c m}$ & \\
\hline Cross section of medium (Excitation) & $A$ & 0.64 & $\mathrm{~cm}^{2}$ & \\
\hline Absorbed length & $a$ & 1.00 & $\mathbf{c m}$ & \\
\hline \multicolumn{5}{|l|}{ Optical parameters } \\
\hline Fresnel lens & & FL(a) & FL(b) & \\
\hline Direct solar intensity & & 922 & 989 & $\mathbf{W} / \mathbf{m}^{2}$ \\
\hline Input solar power & $P_{s n n}$ & 0.87 & 1.86 & $\mathrm{~kW}$ \\
\hline Area of FL distribution & $a$ & 1.87 & 5.37 & $\mathrm{~cm}^{2}$ \\
\hline Maximum solar intensity at focal point & $I_{s a t}=P_{s u n} / a$ & 465 & 347 & $\mathrm{~W} / \mathrm{m}^{2}$ \\
\hline 1064 nmphotons & $\phi_{s e t}$ & $1.1 \times 10^{21}$ & $2.3 \times 10^{21}$ & Photon/s \\
\hline Photon density (Pumping rate) & $R_{p}$ & $5.7 \times 10^{20}$ & $4.3 \times 10^{20}$ & Photon $/ \mathrm{cm}^{3} \mathrm{~s}$ \\
\hline Effective length & $L_{\text {effect }}$ & 1.94 & 4.60 & $\mathbf{c m}$ \\
\hline Mode volume & $V_{a}$ & 1.24 & 2.94 & $\mathrm{~cm}^{3}$ \\
\hline Laser power & $P_{\text {out }}$ & 24.4 & 78.9 & W \\
\hline
\end{tabular}

る最大吸収パワーは $P_{\text {total }}=8 \pi R_{s} l \mathrm{~W}$ と表す事ができる ${ }^{8)}$. 破壊に耐えられる最大パワー密度 $Q_{t h}$ は, 媒質半径 $r$ とす ると $Q_{\mathrm{th}}=8 \pi R_{s} l / \pi r^{2} l=8 R_{s} / r^{2} \mathrm{~W} / \mathrm{cm}^{3}$ と表す事ができる。例 えばフレネルレンズの透過率を $100 \%$ と想定した場合の 媒質単位長さに入射する励起パワー密度 $\left(1000 \mathrm{~W} / \mathrm{cm}^{3}\right)$ に 耐えうるロッド径は $5 \mathrm{~mm}$ 程度となる，有効長を媒質の 全長 $L_{\text {effect }}=10 \mathrm{~cm}$ と仮定して出力ミラーの反射率を変化 させた時のレーザー出力パワーを算出した，出力ミラー の反射率を $90 \%, 80 \%, 70 \%$ とそれぞ変化させた時 の計算結果をFig. 12に示す. 理想的な励起状態が実現し た場合，入力した太陽光パワーが $2500 \mathrm{~W}$ の時，出力ミ ラーの反射率 $80 \%$ が最適で約 $370 \mathrm{~W}$ Wレーザー出力が期 待される.

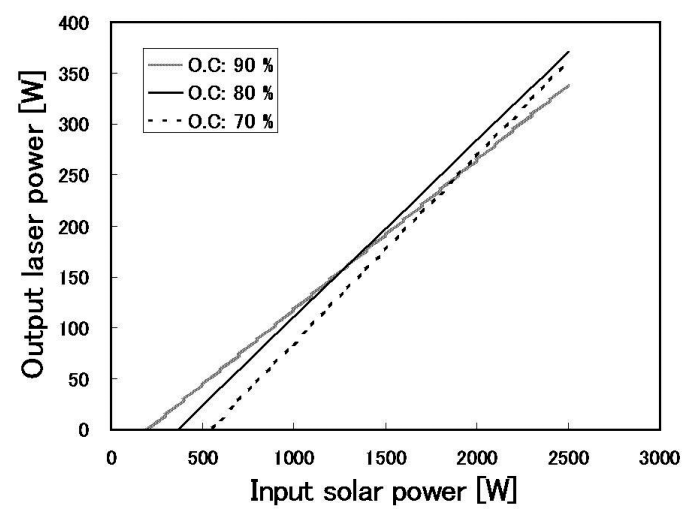

Fig. 12 Laser power of calculated on ideal pumping condition.

\subsection{Total area performance: TAP}

レーザー集光装置の受光面積に対するレーザー出力パ ワーの割合：TAPは，太陽励起レーザー実用化のために 重要な評価指標である。本研究ではFL (a) と FL (b) を用 いた場合にそれぞれ $18.7 \mathrm{~W} / \mathrm{m}^{2}$ と $20 \mathrm{~W} / \mathrm{m}^{2}$ のTAPを実現し ている。 これらの值はFig. 13に示すように従来研究の最 大值であるM. Lando et al. の6.7 W/m ${ }^{25)}$ の2.8倍であり, Cr:Nd:YAGとフレネルレンズを用いた高効率な太陽励起 レーザーの実現に近づきつつある.

$$
\text { 5. まとめ }
$$

世界で初めてフレネルレンズと Cr:Nd:YAG媒質を用い て，高効率で経済的な特長を持つ新しい太陽励起レー ザーシステムを開発した。 Nd:YAG結晶とCr:Nd:YAG

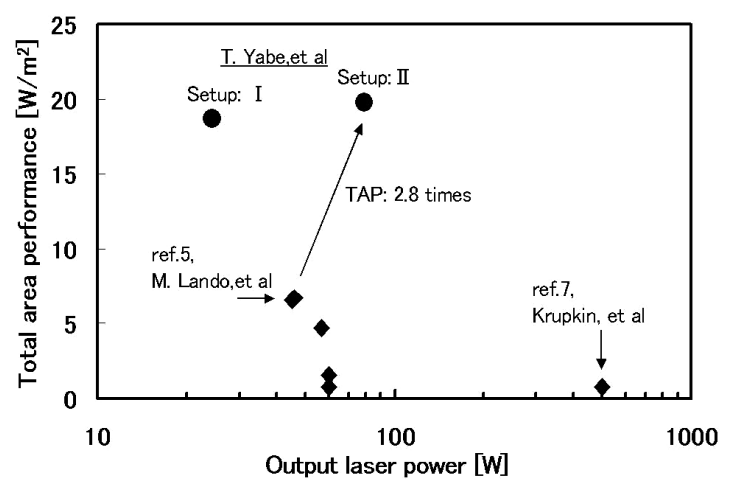

Fig. 13 Total area performance. 
(ドープ濃度 $\mathrm{Cr}: 0.1 \%, \mathrm{Nd}: 1 \%)$ の吸収係数を測定し, 400-500 nm，600-650 nmの波長域でNd:YAG媒質に比べ てCr:Nd:YAGが大きな吸収を持つ事を確認した。太陽光 集光用に開発した4-m²フレネルレンズによる集光像の半 值全幅は2 $1 \mathrm{~mm}$ であり, 色収差を含まない理想的な集光 系による太陽像の大きさとの差が $2.5 \mathrm{~mm}$ であ。この レンズを用いてレーザー発振を行った結果, 入力太陽光 パワー $1860 \mathrm{~W}$ に対して最大で78.9 Wを得た。太陽光か らレーザーへの光変換効率は約 $4.2 \%$ あるる. 太陽光受 光面積に対する割合が $20 \mathrm{~W} / \mathrm{m}^{2}$ となり, 従来の最大值で ある $6.7 \mathrm{~W} / \mathrm{m}^{2} の 2.8$ 倍である。また, レーザー媒質の吸 収と入射太陽光のパワーを考慮した四準位レーザーモデ ルによりレーザー出力の実験值を計算によって再現し， レーザー出力時の励起状態を推定した。 その結果, 市販 レンズにより太陽光を集光した場合では, 長さ $10 \mathrm{~cm}$ の レーザー媒質のうち励起有効長が $1.94 \mathrm{~cm}$ に対し, 新た に設計したフレネルレンズでは $4.6 \mathrm{~cm}$ と励起状態が優れ ている事が明らかとなった．フレネルレンズの集光効率 の改善, 及び媒質が全ての入力パワーを吸収する場合を 仮定し計算を行なった結果, 太陽光パワーが2500 Wの 時, 直径 $5 \mathrm{~mm}$ 長さ $10 \mathrm{~cm}$ の Cr:Nd:YAG媒質では出力ミ ラーの反射率が $80 \%$ で約 $370 \mathrm{~W}$ になると見積もった。数 百Wクラスの太陽励起レーザーユニットが完成すれば, レーザーを集光することによって $\mathrm{MgO}$ の還元が可能と なり，新しいエネルギーサイクルを構築できる.

\section{謝 辞}

太陽励起レーザー実験場の設立に関して，様々なご支 援を頂いた北海道千歳市に感謝の意を表します。また太
陽励起レーザーの開発に関して技術な協力を頂いた(株) ティス，ラフォーレエンジニアリング(株)に感謝しま す.

\section{参考文献}

1) T. Yabe, S. Uchida, K. Ikuta, K. Yoshida, C. Baasandash, M. S. Mohamed, Y. Sakurai, Y. Ogata, M. Tuji, Y. Mori, et al.: Appl. Phys. Lett. 89 (2006) 261107.

2) 矢部孝, 内田成明：レーザー研究 6 (2006) 408.

3) C. G. Young: Appl. Opt. 5 (1966) 993.

4) M. Lando, Y. Shimony, R. M. J. Benmair, D. Abramovich, V. Krupkin, and A. Yogev: Opt. Materials. 13 (1999) 111.

5) M. Lando, J. Kagan, B. Linyekin, and V. Dobrusin: Opt. Comm. 222 (2003) 371

6）湯上 浩雄; 内藤均, 嵐治夫: レーザー研究 24 (1995) 1308.

7) V. Krupkin, Y. Kagan, and A. Yogev: Proc. SPIE 2016 (1993) 50

8) W. Koechner: Solid-State Laser Engineering $6^{\text {th }}$ ed. (Springer, 2006)

9) A. Ikesue, K. Kamata, and K. Yoshida: J. Am. Ceram. Soc. 78 (1995) 2545.

10) T. Yabe, T. Ohkubo, S. Uchida, K. Yoshida, M. Nakatsuka, T. Funatsu, A. Mabuti, A. Oyama, K. Nakagawa, T. Oishi, et al.: Appl. Phys. Lett. 90 (2007) 261120.

11）ASTM：米国材料試験協会G173-03 Reference Spectra Derived from SMARTS v. 2.9.2

12) Y. M. Han, R. Z. Wang, Y. J. Dai, and A. H. Xiong: J. Opt. A: Pure Appl. Opt. 9 (2007) 988.

13) C. Sierra and A. J. Vazquez: J. Mat. Sci. 40 (2005) 1339.

14) O. Svelto: Principles of Lasers $4^{\text {th }}$ ed. (Plenum Press, 1998).

15) T. Saiki, K. Imasaki, S. Motokoshi, C. Yamanaka, H. Fujita, M. Nakatsuka, and Y. Izawa: Opt. Comm. 268 (2006) 155.

16) M. Nakatsuka, H. Yoshida, Y. Fujimoto, K. Fujioka, and H. Fujita: J. the Korean Phys. Soc. 43 (2003) 607.

17) T. Yabe, B. Bagheri, T. Ohkubo, S. Uchida, K. Yoshida, T. Funatsu, T. Oishi, K. Daito, M. Ishioka, N. Yasunaga, Y. Sato, C. Baasandash, Y. Okamoto, and K. Yanagitani: J. Appl. Phys. 104 (2008) 083104. 